\section{Making the annual pilgrimage}

Seven years since it last graced Boston with its presence, the American Association for the Advancement of Science (AAAS) returned there a fortnight ago for its 142nd annual meeting. Roger Woodham reports on a heady week during which some Americans admired their national science effort-and others took it to task

MinORITIES in science, the Viking lander mission to Mars, the inevitable questions surrounding energy policy in general and nuclear power in particular, the views of organisations like Science for the People on everything from genetic manipulation to the busing of schoolchildren ... this is a selection of topics which is at once typical and atypical of the Boston AAAS meeting. Atypical, because few if any of the 5,000-odd attending the meeting will have found it possible to draw all its diverse threads together; but typical, because it represents in a broad-brush fashion the tenor of the whole meeting. Some impressions:

Allied to the whole question of opportunities for minority groups in science -consideration of which included papers like "Spanish-surname Americans in the sciences"-was the matter of women in science, or rather the lack of them. This was the subject of an unusual morning session on Great Women in Science, attended as might or might not be expected by 150 women and 10 men. The message was clear-either, like Margaret Burbidge of the University of California (who has recently been yoted Woman of the Year in California), they had been actively encouraged from an early age, or, like Mildred Dresselhaus of MIT (one of three women members of the National Academy of Engineering), they had simply "stumbled into science and engineering".

When it comes to recognition of female scientists, it transpires that the National Academy of Sciences only does slightly better than its engineering counterpart. It has 21 women members at present, out of a total of 1,144 , and has only ever had 26. But it can claim to have done better than the Royal Society of London in electing its first woman member in 1925 rather than 1948. Equal recognition, the meeting concluded, is as much (if not more) of a problem for women as equality of opportunity.

-One recurrent theme was concerned with the tying together of federal government decisions on tax and economic matters, research and develop- ment, and regulatory policy. Dr William D. Carey (Executive Otticer of the AAAS) contended that the burgeoning of regulations involving industry had led directly to general caution on the part of innovative industrial concerns and the handing down of cautionary decisions. Ninety per cent of industrial research and development is defensive, not imaginative, the declared.

Taking a broadly similar line, Dr Derek C. Bok, President of Harvard University, made remarks that will be echoed by his counterparts on the other side of the Atlantic. He complained that "the government has felt constrained to make painful choices about research priorities; choices that demonstrate the power of the purse to control the growth and shape of the universities". In times of money shortage, he went on, "the needs of institutions of special quality are readily dismissed as elitist and unnecessary". Crash programmes for this or that are all very well, but by focusing attention so heavily on immediate national problems, public officials run the risk of restricting "advances in fundamental knowledge that will leave us illpnepared for the crises yet to come". Echoing Dr Carey, Dr Bok said that declining funds threatened the most novel risk-taking forms of science.

- No fewer than fifteen individuals directly involved in the Viking Mars programme-and one Congressman, Don Fuqua, known to be well disposed towards space science-contributed to a day-long seminar that not only mapped out what the mission hopes to achieve, but reflected, quite soberly, on what may happen next.

Viking, or rather the Vikings, for there were two identical spacecraft launched within a few weeks of each other in October last year, go into orbit around Mars on June 19 and August 7. And as Dr James S. Martin, the Viking project manager, put it, there's no flexibility in that date, whereas the patriotic notion of landing Viking 1 on Mars on July 4, at a place in the Martian Northern Hemisphere appropriately called Chryse ("hope"), could be scrapped if the information sent back from Mars orbit suggested that some other time or place for the landing would be appropriate. Viking 2 is scheduled to land on September 4 (in a different place) but again the Viking 1 lander and the part of it left in orbit would be helping to update Viking 2's final plans.

Everyone seemed to be agreed that the future for the space sciences would in large measure be shaped by the results that come out of the Viking project-not only the photography of the landscape, by cameras capable of a resolution of 2 to 4 millimetres, but also the outcome of scooping up Martian soil and feeding it on a "rich organic soup", among other things, to see if there are any signs of life.

If there were, that might also be the signal for renewed activity in the search for extraterrestrial intelligenceanother seminar topic which saw AAAS participants packed in the aisles. The idea of spending $\$ 10,000$ million on Project Cyclops, a giant 'listening' programme, is one that is pretty well buried, but more modest schemes to carry on and expand the listening work of the Arecibo radio telescope would undoubtedly blossom if Viking struck lucky.

Assuming some middle-of-the-road outcome for the Viking project-which certainly means no photographs of footprints-and bearing in mind the constraints of the NASA report Outlook for Space, which lays down those classes of project that should be attempted-what alternative ways ahead are there? More Vikings of the same kind, Vikings that can be mobile on the Martian surface, Vikings that drop penetrometers from orbit (instrument packages capable of burying themselves hundreds of metres down in the right conditions and sending back data such as temperatures), Vikings that can return a shovelful of Martian soil to Earth-all these are possibilities, as is further collaboration with the Soviet Union. But what everyone seems to be ruling out is landing a man on Mars, at least before the year 2000. That would undoubtedly violate NASA's guidelines for space research in the last twenty years of the twentieth century. -Science for the People-a radical group that can see very little right in American science, it seems-has almost made it into the Establishment of the AAAS. During the past five years or so it has had a tolerate-hate relationship with the association at annual meetings, sometimes involving the police; this year it had its seminars formally included in the AAAS programme. Science for the People will snipe at anything-including Boston's school busing problem and the cost of electricity-but at the Boston meeting it was mainly addressing itself to topics like cancer research. The group asked, in one of its sessions, for example: "Why has so little effort been devoted to the problem of preventing cancer caused by occupational and environmental agents, when it is widely recognised that 80 to $90 \%$ [sic] of all cancer is caused this way?" 